DOI 10.37882/2223-2982.2021.11.40

\title{
НЕКОТОРЫЕ ОСОБЕННОСТИ ВОССТАНИЯ ПОД РУКОВОДСТВОМ ГАЙНЫ В КОНТЕКСТЕ ПОПЫТКИ ГЛАВНОГО МЯТЕЖНИКА УСТАНОВИТЬ В РИМСКОЙ ИМПЕРИИ ТИРАНИЧЕСКОЕ ПРАВЛЕНИЕ
}

\section{SOME FEATURES OF THE REBELLION UNDER THE LEADERSHIP OF GAINAS \\ IN THE CONTEXT OF THE MAIN REBEL'S ATTEMPT TO ESTABLISH A TYRANNICAL RULE IN THE ROMAN EMPIRE}

S. Yartsev

Summary: The article looks into the complex topic of the Gainas' rebellion on the territory of the Eastern Roman Empire at the end of the 4th century. The author considers the events of this period in the context of an attempt of the main rebel to establish a tyrannical rule in the state. Based on the evidence from the sources that have come down to us, the author concludes that it is necessary to divide the events of the Gothic rebellion into two stages. According to the author, the characteristic feature of the first stage is the coordination of the actions of Stilicho and Gainas in organizing the Gothic conspiracy. At the same time, the latter, at the peak of the Gothic rebellion, was supposed to invite the western commander, along with his army, to Constantinople. However, instead of being invited, the de facto ruler of the Western part of the state was forced to observe the phenomenal rise of Gainas, who very quickly became in the East what Stilicho himself was in the West.

From this moment, when from an ally Stilicho turns into an enemy of the Goths, the second stage of Gainas' rebellion begins. Sources indicate that at this stage Stilicho focused his efforts on two areas of his political activity: in relations with the ruling elite of Constantinople, and in relations with the barbarian world. In the first direction, ignoring the government of Aurelius, Stilicho demanded to recognize his power in the East, offering help against the Goths for this. In the second direction, he stepped up the army reforms, among which he began to conduct a wide recruitment of the Sarmatians and Alans into the army. Perhaps, at the same time, Stilicho established friendly relations with the Huns, which in turn may indirectly testify in favor of the existence of plans for a Gothic invasion of the territory of the Roman Empire. The realization that only the Huns and the Alans could effectively oppose the Goths, both inside the empire and outside it, apparently became the main determining factor in many of Stilicho's actions towards the barbarians during this period. Ultimately, Gainas decided not to wait for the start of the mass migration of his fellow tribesmen to Roman territory, which was delayed, apparently, due to their defeat from the Huns. According to the author, it is this circumstance that explains the mysterious features of subsequent events, when the Goths who remained in the city tried to secretly set fire to the imperial palace, and other participants in the conspiracy made an attempt to blame the opposition for this, seeking to destroy people from the circle of Aurelian's anti-Gothic party. Gainas' mistakes and the haste with which he acted at the final stage of the rebellion did not allow him to rely solely on his own forces to establish a tyrannical form of government in the Empire.

Keywords: The Roman Empire, Stilicho, Gainas, Tribigild, Alaric, the Goths, the Huns, the Alans.

\author{
Ярцев Сергей Владимирович \\ Д.и.н., дочент, Тульский государственный педагогчческий \\ университет им Л.Н. Толстого \\ s-yartsev@yandex.ru
}

Аннотация: Статья посвящена сложной теме восстания Гайны на территории Восточной Римской империи в конце IV в. События данного периода рассматриваются автором в контексте попытки установления главным мятежником тиранического правления в государстве. На основании свидетельств дошедших до нас источников, автор приходит к выводу о необходимости разделения событий готского мятежа на два этапа.

Характерной особенностью первого этапа, по мнению автора, является согласованность действий Стилихона и Гайны в организации готского заговора. При этом последний на пике готского восстания, должен был пригласить западного командующего, вместе со своей армией, в Константинополь. Однако вместо приглашения, фактический правитель западной части государства был вынужден наблюдать феноменальное возвышение Гайны, который очень быстро стал на Востоке, тем, кем являлся на Западе сам Стилихон.

С этого момента начинается второй этап восстания Гайны, когда из союзника, Стилихон превращается во врага готов. Источники свидетельствуют, что на данном этапе Стилихон сосредоточил свои усилия на двух направлениях своей политической деятельности, В отношениях с правящей элитой Константинополя, и во взаимоотношениях с варварским миром. На первом направлении, проигнорировав правительство Аврелия, Стилихон потребовал признать свою власть на Востоке, предложив за это помощь против готов. На втором, он активизировал армейские реформы, в числе которых, начал проводить широкий набор в армию сарматов и аланов. Возможно, одновременно с этим Стилихон установил дружественные отношения с гуннами, что в свою очередь косвенно может свидетельствовать в пользу наличия планов готского вторжения на территорию Римской империи. Осознание того, что эффективно противодействовать готам, как внутри империи, так и за ее пределами, могли лишь гунны и аланы, по-видимому, и стало главным определяющим фактором многих действий Стилихона по отношению к варварам в указанный период. В конечном итоге Гайна решил не дожидаться начала массовой миграции своих соплеменников на римскую территорию, задержка которой произошла, по-видимому, из-за поражения последних от гуннов. По мнению автора, именно данным обстоятельством объясняются загадочные особенности последующих событий, когда оставшиеся в городе готы, пытались тайно поджечь императорский дворец, а другие участники заговора обвинить в этом представителей оппозиции, стремясь уничтожить людей из круга антиготской партии Аврелиана. Допущенные Гайной ошибки и спешка, с которой он действовал на заключительном этапе восстания, не позволили ему с опорой исключительно на свои силы, установить тираническую форму правления в империи.

Ключевые слова: Римская империя, Стилихон, Гайна, Трибигильд, Аларих, готы, гунны, аланы. 
События, связанные с восстанием готов Гайны и Трибигильда на территории Восточной Римской империи в конце IV в., до сих пор продолжают вызывать интерес среди ученых. Однако, несмотря на значительное количество трудов, еще многие вопросы истории римского государства данного периода, остаются нерешенными $[2 ; 4 ; 5 ; 7 ; 8 ; 9 ; 10 ; 12 ; 15 ; 16 ; 19 ; 21 ; 23]$. Особенно сложным вопросом при изучении данной темы, является определение конечной цели главного мятежника, военного магистра Гайны. Вопреки сведениям источников (Zosim., V, 17, 4-5, 18, 9-10; Socr., VI, 6; Soz., VIII, 4; Theodor., V, 32), существует мнение, что Гайна не стремился к власти в форме тирании, а лишь хотел занять положение, которое занимал Стилихон на Западе [21, р. 197; 22, р. 197].

Тем не менее, представляется, что план Гайны по установлению тиранического правления в Римской империи, выглядел достаточно продуманным и реалистичным. И это несмотря на довольно впечатляющий результат, на который он был нацелен. Во всяком случае, многие особенности событий начавшегося мятежа, можно интерпретировать, только допуская наличие указанной масштабной, амбициозной цели могущественного гота. Так, вначале Гайна разделался с армией Льва, окружившей Трибигильда, разослав «отряды своих варваров по разным римским лагерям, чтобы они поочередно напали на них, что дало бы шанс Трибигильду спастись. Эти варвары, которых Гайна послал Льву как вспомогательные союзные войска, напали на всех римлян, опустошили страну и убивали солдат. Они не прекратили своих решительных атак до тех пор, пока не уничтожили армию Льва и их полководца» (Zosim., V, 17, 1-2). Далее Гайна, вполне предсказуемо сообщил императору, что «будучи не в силах противостоять ярости Трибигильда», он не может «освободить Азию от опасности», из-за чего необходимо «передать ему правителя Евтропия - виновника всех бедствий - для того, чтобы расправиться С ним по своему произволу» (Zosim., V, 17, 5). При поддержке императрицы Евдоксии, осенью 399 г. Евтропий был снят с должности и вначале отправлен в ссылку на Кипр (Zosim., V, 18, 1; Socr., VI, 6; Theodor., V, 32; Cod. Theod. IX, 40,17), а затем, по настоянию Гайны, казнен (Zosim., V, 18, 2-3; Socr., VI, 5; Soz., VIII, 7; Philost., XI, 6; Cod. Theod. IX, $40,17)$. Безусловно, что на этом этапе Гайна получил поддержку большого круга представителей оппозиции правительству Евтропия, включая даже приверженцев «антиготской партии», как ни парадоксально это выглядело [7, с. 78-79]. Фактически была разгромлена вся группировка могущественного евнуха $[7$, с. $79 ; 16$, с. 196; 14 , с. 109; 17, с. 85]. Часть бывших друзей последнего смогла бежать, часть предусмотрительно превратилась в его врагов (loh. Chrys. In Eutr., 1; loh. Chrys. De capto Eutrop., $3,4)$.

Заменивший Евтропия, глава антиготской партии префект претория Востока Аврелиан, довольно силь- но рисковал, когда в тревожной ситуации 399 года осмелился возглавить consistorium. Хотя, по-видимому, в это время он не воспринимал реальной опасности, так как не был посвящен в планы Гайны и совершенно бесстрашно продолжал свою враждебную политику по отношению к готам. Аврелиан даже взял за правило демонстративно унижать Гайну, принципиально не приглашая его к участию в императорском совете [16, с. 197]. В конечном итоге «когда Гайна взял Халкидон, а Трибигильд - окрестности Лампсака, то Константинополь и вся Римская империя оказались в большой опасности. Гайна потребовал к себе императора», которому пришлось встретиться с могущественным готом и выдать ему «для казни» Аврелиана и других известных лиц антиготской партии (Zosim., V, 18, 6-8). Хотя казнь была не настоящая - Гайна лишь прикоснулся мечом к шеям своих врагов (Zosim., V, 18, 9), последние были нейтрализованы и отправлены в изгнание. Сам же Гайна получил звание magister utriusque militiae in praesentalis с полным правом командования «пехотой и конницей» (Soz., VIII, 4-5), и обещание консульства на следующий 401 г. Со своей огромной армией он вступил в Константинополь (Zosim., $\mathrm{V}, 18,10)[21$, р. 252], безусловно поднявшись на вершину своего могущества [17, с. 86]. К этому времени Лев и Трибигильд уже умерли (Zosim., V, 17, 2; Philost., XI, 8) и главнокомандующий вооруженными силами Востока, окончательно сосредоточил управление восточной армией в своих руках. Аларих и Фравитта вынуждены были подчиниться своему новому командующему [23, р. 170-171].

Если верно наше предположение о наличии масштабных планов Гайны о массовом переселении готов Северного Причерноморья на территорию Римской империи, с целью установления с опорой на соплеменников тиранической власти в государстве, то Стилихон обязан был предпринять ответные действия, так как это не только разрушало его собственные замыслы, но и создавало угрозу существования всей империи. Видимо, когда началось восстание Трибигильда Стилихон еще действовал в рамках договоренностей с Гайной, обеспечивая идеологическую часть операции. При этом последняя, как он думал, заключалась исключительно в устранении Евтропия в ходе приглашения его, вместе с западной армией, в Константинополь. С этой целью поэту Клавдиану, Стилихоном было дано указание начать атаку на Евтропия [16, с. 191]. Ситуация здесь облегчалась тем, что буквально накануне Евтропий, будучи евнухом, смог добиться своего назначения консулом на 399 год, что вызвало справедливый гнев и возмущение по всей империи. Данный факт, самым негативным образом, сработал против всемогущего евнуха и был максимально использован для очернения его образа Клавдианом и Стилихоном (Claud. Eutrop., I). Однако, мнение, что только с провозглашения Евтропия консулом и начался новый период конфронтации между ним и Стилихоном [16, с. 191-192], вряд ли можно считать верным. Скорее 
всего, начало пропагандистской акции против Евтропия было приурочено к готскому восстанию второй половины 399 года и должно было, по сути, его предварять. В противном случае, невозможно будет объяснить, почему Стилихон, являясь достаточно активным политическим деятелем, после поражения 397 года от Евтропия, якобы теряет интерес к делам на Востоке и отказывается от достижения своих амбициозных планов. Выходит, что если бы Евтропий не стал бы консулом, Стилихон и не подумал бы о новом противостоянии с фактическим правителем Востока. Согласимся, что это выглядит неправдоподобно. Если Стилихон с самого начала являлся участником заговора то, по сути дела, он и должен был произвести первые действия по свержению Евтропия, обрушив на противника, умело обработанный поток истинных и ложных обвинений, что, по всей вероятности, и произошло.

Однако вместо приглашения в Константинополь, фактический правитель западной части государства стал наблюдать феноменальное возвышение Гайны, который очень быстро стал на Востоке, тем, кем являлся на Западе сам Стилихон. Если допустить, что Стилихон в это время, помимо предательства Гайны, в какой-то степени, еще узнал и о враждебных планах могущественного гота по отношению к Римской империи, то он просто обязан был предпринять ответные меры по спасению государства. Именно с этого момента начинается второй этап готского восстания, когда из союзника, Стилихон превращается во врага готов. Политика Стилихона в это время, проводится по двум основным направлениям, по отношению, собственно, к правящей элите Константинополя, и по отношению к варварам. Так, из текста второй книги «Против Евтропия», написанной Клавдианом в сентябре 399 г., нам известно, что Стилихон, игнорируя правительство Аврелия [22, р. 210], требует признать свою власть на Востоке, по сути предлагая помощь против готов: «Воссияла лишь одна надежда на спасение - Стилихон... все хотят, чтобы он явился к ним, раскаиваясь в своих прежних преступлениях» (Claud. Eutrop., II, 500-510) [16, c. 200]. При этом, так как все законодательные акты Евтропия утратили свою силу (Cod. Th., IX, 40, 17), Стилихон решает выдвинуть свою кандидатуру на консульство на 400 г. [25, р. 77]. Что же касается политики по отношению к варварам, то Стилихон в данный период активизирует армейские реформы, которые предусматривали отзыв с границ верных римских воинских подразделений с повышением старшинства и привилегий и передислокацию их во внутренние районы государства [16, с. 176-178]. Одновременно был объявлен широкой набор в армию из числа варваров. Судя по закону января 400 г. к военной службе необходимо было привлечь «любые laetus, allamannus, сарматов, бродяг, сыновей ветеранов или любых представителей другой группы, подлежащих призыву на военную службу» (Cod. Th., VIl, $20,12)$. Таким образом, политика пополнения римской армии варварами получила в это время свое логическое завершение. Стилихон упорядочил зачисление в армию варварских вспомогательных подразделений во главе с их собственными вождями [16, с. 182]. Однако обращает на себя внимание, что основной упор был сделан не на готов, а на сарматов, аланов (Claud. IV Cons., 485-487, Get., 580-583) и даже франков (Claud. Eutr., 381-383). По ценному наблюдению Ю.А. Кулаковского, которое В наши дни было поддержано А.В. Банниковым и М.А. Морозовым, причиной этого, могло быть установление Стилихоном в данное время дружественных отношений именно с гуннами $[11$, с. 90; 1, с. 216]. В любом случае, такая политика по отношению к кочевникам со стороны правителя Запада, косвенно подтверждает наличие планов готского вторжения на территорию Римской империи, в том числе и в западную ее часть. Дело в том, что эффективно противодействовать готам могли лишь гунны и аланы, следовательно, именно это обстоятельство и должно было определять многие действия Стилихона в указанный период. Несмотря на то, что Йен Хьюджес объясняет передислокацию войск исключительно внутренними причинами (например, сопротивлением Сената, желающим видеть свою армию «римской» по своему составу), особенности такой перегруппировки, наводят на мысли, что Стилихон в данное время, по-видимому, реально ожидал серьезного удара по Италии с востока и делал все возможное, чтобы защитить, в первую очередь, именно территорию Апеннинского полуострова. Видимо, не случайно в Италии были сосредоточены лучшие отборные римские войска, тогда как нанятые варварские вспомогательные подразделения, по большей части, размещались на границе в Галлии и Германии [16, c. 182].

Таким образом, успех проводимых Стилихоном военных реформ на Западе, а также очевидная задержка с подходом к римским границам готов Северного Причерноморья, привели Гайну к осознанию невозможности достижения своей цели старыми способами. Конечно, высокопоставленного гота, быстро поднявшегося на вершину власти, уже сейчас можно было назвать узурпатором [21, р. 252-253]. Однако на самом деле, он был еще очень далек от своей конечной цели - достижения неограниченной власти. По-видимому, установлению тиранического правления Гайны, стала мешать начавшаяся затяжная война или даже поражение готов Северного Причерноморья от гуннов и отсюда невозможность осуществить быструю переброску своих соплеменников на территорию Римской империи. Новый префект претория Востока Кесарий, хотя и был обвинен оппозицией связанной с Аврелианом в поддержке варваров (Syn. De prov.), на самом деле, использовал последних исключительно ориентируясь на интересы военно-чиновной знати своего круга [8, с. 26-27]. Из-за всего этого, Гайна не обладал всей полнотой власти в государстве на Востоке, и принимать единоличные решения, по многим вопро- 
сам, не мог. Несмотря на высокую должность, которую он занимал, ему не удалось даже передать своим готамарианам одну из столичных церквей (Soc., VI, 5; Soz., VIII, 4). Несмотря на то, что к такой уступке склонялся сам император, явно боявшийся могущественного гота (Theod., V, 32), Иоанн Златоуст резко выступил против, настояв не «отдавать святая псам». По его словам, нельзя было допустить «чтобы исповедующие и прославляющие БогаСлова выведены были из божественного храма и сдали его хулителям Христа» (Theod., V, 32). При этом заметим, что Иоанн Златоуст достаточно много уделял внимания духовному развитию готов, как в центре, так и на периферии римского мира, правда, только при условии согласия варваров на организацию у них ортодоксальной церкви, с богослужением на готском языке [18, с. 93-98; 27, р. 374-379; 13, с. 112-114]. В любом случае, не вызывает сомнений наличие в это время явной и скрытой оппозиции готам из числа представителей господствующей знати, находившейся у власти в Константинополе. Данный факт следует хотя бы из речи Синезия, обращенной к императору Аркадию в 399 г. (Syn. De Regno). Евдоксия же, вообще вопреки желанию Гайны 9 января 400 г. была коронована августой (императрицей) [16, с. 198].

По-видимому, чтобы устранить или даже полностью ликвидировать настроенных против готов римлян, Гайна решил не дожидаться начала массовой миграции своих соплеменников на римскую территорию. Однако, последующая его тактика, как и отдельно предпринятые действия, не совсем понятны. К сожалению, недосказанность и противоречивость дошедших до нас сведений, касающихся этого заключительного этапа готского мятежа, стали причиной появления в историографии различных интерпретаций указанных событий, нередко не выдерживающих никакой критики. Наиболее распространенная версия объясняет загадочное разделение Гайной своей армии, попытку готов поджечь императорский дворец и последующую гибель последних, исключительно стремлением варваров к грабежу [20, р. 174; 15 , с. $59-60 ; 16$, с. $198 ; 14$, с. 109-111]. Правда, на резонный вопрос, зачем понадобилось Гайне атаковать город, которым он уже обладал [3, с. 218, прим. 5], вразумительного ответа, никто дать так и не смог.

Тем не менее, тексты дошедших до нас источников недвусмысленно свидетельствуют о реальном разделении Гайной своего войска, еще до событий избиения готов в городе. Так, исходя из текста Зосима, чтобы дистанцироваться от планируемого им же самим восстания, Гайна «внедрил своих людей повсюду так, что в городе не было даже дворцовой охраны, а также тайно приказал своим варварам: когда они увидят, что воины покинули город, немедленно захватить его, пока он пребывает беззащитным, и передать ему высшую власть в столице». Таким образом, летом 400 г. «отдав своим варварам приказ для выполнения, Гайна покинул город ... удалился в окрест- ности на расстоянии в сорок миль, откуда он намеревался совершить нападение после того, как варвары восстанут по его сигналу» (Zosim., V, 18, 10;19, 1-3).

Очевидно, что такой, на первый взгляд, запутанный ход событий заключительного этапа готского мятежа, безусловно, не случаен. Перед нами явно хорошо организованная и продуманная операция, наиболее важной частью, которой и было разделение Гайной своих сил. Тем более что сведения о разделении готского войска, фигурируют не только у Зосима, но и у других авторов. Так, учеными было замечено, что Евнапий фактически подтверждает версию Зосима об уходе Гайны из Константинополя, еще до всех основных событий в городе [10, с. 247]. Синезий похожим образом пересказывает данные события, утверждая, что когда на готов напали горожане, многие из них «уже ушли, но вскоре вернулись, чтобы помочь своим соплеменникам» (Syn. De prov., II, 2). Здесь весь иносказательный рассказ о варварах, которые были «остановлены у выхода, когда они собирались или уже ушли» (Syn. De prov., II, 2), как раз и мог быть навеян реальным фактом разделения готского войска, еще до событий столкновения с горожанами. У того же Созомена, также отмечено, что когда «одни из варваров остались в городе, ... другие вышли вместе с Гайною» (Soz., VIII, 4). Тем не менее, церковные историки при описании данных событий, явно нарушают их хронологию, создавая серьезные противоречия в ходе реконструкции финальной части готского мятежа. Правда, их можно понять, ведь это делалось не специально, а с целью акцентирования внимания на божественной помощи городу (Socr., VI, 6; Soz., VIII, 4).

Если же исходить из тщательного анализа источников, вернее всего будет предположить, что в установленное время, оставшиеся в городе готы, должны были тайно поджечь императорский дворец (Socr., Vl, 6) или совершить его попытку захвата [26, р. 380]. После этого другие участники заговора (Кесарий и его люди?) используя обвинение в нападении на императора, расправились бы с ведущими представителями оппозиции из круга антиготской партии Аврелиана. В последующих действиях Гайны по наведению порядка, оппозиция явно подверглась бы окончательному разгрому, а в государстве была бы установлена тираническая форма правления. Однако этот гениально разработанный план не сработал. Судя по всему, люди Аврелиана оказались, не только хорошо осведомлены о планах своих врагов, но и в значительной степени проворны, если успели в нужный момент собрать неожиданное большое количество воинов у императорского дворца (Socr., VI, 6; Soz., VIII, 4). Сомнительно, что эти люди были исключительно посланы церковью [15, с. 60], вернее предположить о предпринятых вовремя контрмерах оппозиционно настроенной знатью. В пользу этого, косвенно свидетельствуют хорошо продуманные действия императора, который 
сразу же после начала, казалось бы, спонтанного сражения горожан с оставшимися в городе готами и успешной защиты ворот от подошедшего Гайны, довольно неожиданно и главное смело объявляет последнего врагом государства «воспользовавшись спасительным советом» (Socr., Vl, 6). Видимо, не случайно, в это же время, люди Аврелиана заговорили о необходимости возвращения последнего из ссылки [21, р. 258, n. 129; 8, с. 28-29].

Конечно, мы не можем исключить из числа виновников провала мятежа и собственно Гайну. Видимо напрасно «вместо того, чтобы ждать сигнала, он приблизился к стене, а устрашенные стражники подняли тревогу ... варваров убивали мечами, камнями и всем, что попалось под руку. Жители взобрались на стену и помогали воинам тем, что швыряли в людей Гайны все, что могли найти, и вот таким образом они отразили нападение на город. Так город избежал опасности, а варвары, которые находились внутри, были вырезаны горожанами. Более семи тысяч нашли убежище самостоятельно, спрятавшись в христианской церкви близ дворца. Император приказал, чтобы их убили... решено было сдвинуть крышу над алтарем, чтобы специально посланные люди могли сбросить вниз на укрывшихся горящие головешки. Все это делалось до тех пор, пока враги не сгорели» (Zosim., V, 19, 3-4). С небольшими вариантами, другие источники подтверждают факт массового убийства оставшихся в городе готов (Soc., V, 6; Soz., VIII, 4; Theod., V, 32-35).

Впоследствии Гайна, при попытке переправиться в Малую Азию, где он, очевидно, вновь хотел поднять готов, был наголову разбит Фравитой (Zosim., V, 20, 21; Marcell. Chron., 400). Разумеется, еще не все было потеряно, но уйти на Запад к Стилихону, из-за предательства последнего в ходе восстания, Гайна уже не мог. Единственным возможным для него выходом из создавшейся ситуации, было отступление к варварам Северного Причерноморья, по-видимому, сражавшимся в это время с гуннами. Судя по тому, что Гайна убил всех своих солдат римлян, вероятно, он хотел вернуться обратно уже как военный предводитель огромной армии готов. Впрочем, Зосим объясняет это убийство простым опасением возможного предательства, так как «другая римская армия могла последовать за ним и атаковать оставшихся у него людей» (Zosim., V, 21, 6). Беспокойство Гайны из-за малого количества своих воинов было не напрасно. Как только он перешел Дунайский лимес он был атакован гуннами Ульдина, по-видимому, прекрасно осведомленными о цели появления готов в своих владениях. Очевидно, Гайна не столько хотел возродить независимое готское государство [4, с. 216], сколько планировал совершить вторжение на территорию империи и рассчитаться сполна со всеми своими врагами. «Армия Гайны держалась до конца, но многие из воинов пали, включая самого Гайну, который сражался решительно и отважно... Ульдис, вождь гуннов, послал его голову императору, за что и был награжден» (Zosim., V, 22, 1-3) [24, p. 59].

Таким образом, Гайну сложно назвать дилетантом, а его действия характеризовать, как лишенные рационального содержания. Его проект был вполне осуществимым, хотя и был крайне опасен по своим последствиям для Римской империи. Очевидно, что только неудачное стечение обстоятельств, недооценка сил оппозиции, неправильная политика по отношению к местному населению, вызвавшая ответное враждебное отношение к варварам, а также серьезное сопротивление гуннов, судя по всему, разбивших готов Северного Причерноморья и, в конечном итоге, убивших самого Гайну, не позволили осуществиться его грандиозным замыслам. Однако, именно в связи с масштабом задуманного Гайной, правящая элита осознала огромную опасность для государства, насильственно внедренного в него варварского элемента. Скорее всего, именно по этой причине, когда партия Аврелиана и Евдоксии восстановила свою власть [6, с. 469; 16, с. 198], она потребовала критического пересмотра ошибочной, по их мнению, политики по отношению к готам, начиная еще с Феодосия I, и стала добиваться прекращения практики массового привлечения варваров к службе в армии и расселения их в отдельных компактных регионах (Syn. De Regno).

\section{ЛИТЕРАТУРА}

1. Банников А.В., Морозов М.А. Византийская армия (IV-XII вв.). СПб.: Евразия, 2017. 688 с.

2. Богданов Д.Е. Борьба западного и восточных дворов Римской империи в конце IV века // Научные ведомости БелГУ. Серия История. Политология. 2017. №22. C. 41-45.

3. Болгов Н.Н. (ред.). Зосим. Новая История / Перевод, комментарии, указатели. Белгород: Издательство БелГУ, 2010. 344 с.

4. Вольфрам Х. 2003. СПб.: Ювента, 2003. 656 с.

5. Глушанин Е.П. Военная знать ранней Византии. Барнаул: Алт. кн. изд-во, 1991. 246 с.

6. Голдсуорти А. Падение Запада. Медленная смерть Римской империи. М.: АСТ, 2014.733 с.

7. Козлов А.С. Борьба между политической оппозицией и правительством Византии в 395-399 гг. // Античная древность и средние века. Свердловск, 1976. Вып. 13. С. 68-82.

8. Козлов А.С. Основные черты политической оппозиции правительству Византии в 399-400 гг. // Античная древность и средние века. Свердловск, 1979. 
Вып. 16. С. 23-31.

9. К Коньков Д.С. Готы на территории Римской империи: трансформация этно-потестарной идентичности. Северск: Изд-во СТИ НИЯУ МИФИ, 2011. 151 с.

10. Коньков Д.С. Готы и империя: восстание Гайны как кризис идентичности // Известия Томского политехнического университета. 2012. Т. 321 №6. С. 244-249.

11. Кулаковский Ю.А. Избранные труды по истории аланов и Сарматии. СПб.: Алетейя, 2000. 318 с.

12. Ляховская 0.В. Готы в Константинополе: мятеж Гайны 399-400 гг. // Научные ведомости БелГУ. Серия История. Политология. Экономика. Информатика. 2011. №13. Вып. 19. С. 35-38.

13. Пикин А.В. Политические миссии церковных деятелей в системе посольского взаимодействия конца IV - первой четверти VI века. Дисс. ... канд. ист. наук. Иваново, 2016. 195 C.

14. Пржигодзкая 0.В. К вопросу о мятежах в Римской империи в IV в.: восстание гота Гайны в Константинополе в $399-400$ гг. // Вестник Санкт-Петербургского университета. 2013. Сер. 2. Вып. 1. С. 107-112.

15. Сиротенко В.Т. Борьба Западной Римской империи и Византии за префектуру Иллирик в 395-425 гг. и ее последствия // Античная древность и средние века. Свердловск, 1972. Вып. 8. С. 73-88.

16. Хьюджес Й. Стилихон. Вандал, который спас Рим. М.: Изд-во «Клио», 2017. 352 с.

17. Чекалова А.А. Варварский элемент в Византии (IV-V века) // Цивилизация и варварство: механизмы, инструменты и субъекты взаимодействия. М.: Аквилон, 2014. Вып. III. С. 75-102.

18. Ярцев С.В. Письмо константинопольского архиепископа Иоанна Златоуста диаконисе Олимпиаде как важнейший источник по истории раннего христианства на Боспоре // Вестник ГОУ ДПО Т0 «ИПК И ППРО Т0» Тульское Образовательное Пространство. Тула, 2018. №1. С. 93-98.

19. Cameron A. Claudian: Poetry and Propaganda at the Court of Honorius. Oxford: Clarendon press, 1970.508 p.

20. Cameron A., Long J., Sherry L. Barbarians and Politics at the Court of Arcadius (The transformation of the classical heritage XIX). Berkeley: University of California Press, $1993.411 \mathrm{p}$.

21. Demougeot E. De l'unité à la division de l'empire romain, 395-410. Paris: Adrien-Maisonneuve, 1951. 618 p.

22. Heather P.J. Goths and Romans, 332-489. 0xford: Clarendon Press, 1991. 378 p.

23. Liebeschuetz J.H. W.G. Barbarians and Bishops: Army, Church and State in the Age of Arcadius and Chrysostom. Oxford: Clarendon Press, 1990. 312 p.

24. Maenchen-Helfen 0. The World of the Huns: studies in their history and culture. Berkeley: University of California Press, 1973. 602 p.

25. Matthews J. Western Aristocracies and Imperial Court A.D. 364-425. 0xford: Clarendon Press, 1975. 427 p.

26. The Prosopography of the Later Roman Empire, I: A.D. 260-395 / Edited by A.H.M. Jones, J.R. Martindale and J. Morris. Cambridge: Cambridge University Press, 1971. $1152 \mathrm{p}$.

27. Yartsev S., Zubarev V., Smekalov S. The Christian goths at the bosporus in the 4th and 5th centuries AD // Journal of Social Sciences Research. Special Issue. 2018. №3. P. 374-379. 